\title{
BMJ Open Determinants of childhood vaccination in Nagaland, India: a cross-sectional study with multilevel modelling
}

\author{
Young Eun Kim (D)
}

To cite: Kim YE. Determinants of childhood vaccination in Nagaland, India: a crosssectional study with multilevel modelling. BMJ Open 2021;11:e045070. doi:10.1136/ bmjopen-2020-045070

- Prepublication history and supplemental material for this paper is available online. To view these files, please visit the journal online (http://dx.doi org/10.1136/bmjopen-2020045070).

Received 22 September 2020 Revised 23 March 2021 Accepted 29 March 2021

Check for updates

(C) Author(s) (or their employer(s)) 2021. Re-use permitted under CC BY-NC. No commercial re-use. See rights and permissions. Published by BMJ.

Development Research Group and EAPCE Research Center, World Bank, Kuala Lumpur, Malaysia

Correspondence to

Young Eun Kim;

ykim10@worldbank.org

\section{ABSTRACT}

Objectives Childhood vaccination coverage in Nagaland has lagged almost all states in India for more than two decades. This study aims to find drivers and barriers of childhood vaccination in Nagaland from the perspective of demand, supply and local health governance.

Design A cross-sectional study was designed using a survey conducted by the Directorate of Health and Family in 2015.

Setting Households, community-based health centres and health committees were surveyed.

Participants 285 children aged under 2 years with vaccination cards and data on households, health centres and health committees were included.

Outcomes Variables indicating whether a child received each of bacilluscalmette-guérin (BCG), diphtheriatetanus-pertussis (DTP3), oral polio (OPV3) and measles vaccination and all of them were outcome variables. Associated factors were identified using multilevel logistic regressions.

Results Antenatal care at least three times was significantly associated with BCG, DTP3, OPV3 and full vaccination with adjusted ORs ranging from $2.4(95 \%$ Cl 1.1 to 5.1 ) to 3.3 (1.1 to 9.9). The availability of bus to health centre was slightly significant for BCG and OPV3 with the adjusted ORs of 2.0 (0.9 to 4.5) and 2.1 (0.9 to 4.8), respectively. Health committees' budget provision to health centres was significant for OPV3 and full vaccination with the respective adjusted ORs of 15.7 (1.0 to 234.1) and 15.9 (1.2 to 214.7), the wide 95\% Cls of which were driven by a small sample size. Health committees' review of expenditure of health centres was significant for measles and full vaccination with the adjusted ORs of 4.0 (1.4 to 11.4) and 5.2 (1.4 to 19.4), respectively.

Conclusion This study suggests that enhancing the utilisation of antenatal care and providing reliable transportation between villages and health centres are required to improve childhood vaccination coverage. Also, the significant association of budget administration of health committees suggests that supporting local health committees for effective financial management is important.

\section{INTRODUCTION}

Childhood vaccination coverage has been increasing for decades globally. For instance, the WHO reported that the coverage of three

\section{Strengths and limitations of this study}

This is the first study to examine determinants of childhood vaccination in the state of Nagaland, India, from the perspective of demand, supply and local health governance.

- This study used multilevel logistic regressions to analyse survey data collected with a multistage cluster sampling method.

- Given the cross-sectional study design, causality from significant factors to vaccination coverage could not be proved.

- Data were not representative of entire households, health centres and local health committees in Nagaland.

doses of diphtheria-tetanus-pertussis (DTP3) vaccine among infants increased from $20 \%$ to $85 \%$ over the period $1980-2019$ at the global level. ${ }^{1}$ However, the coverage at national and subnational levels has varied across countries. India's latest National Family Health Survey in 2015-2016 (NFHS-4) showed that average DTP3 coverage was $78.4 \%$ at the national level; however, the coverage ranged from $51.6 \%$ (Nagaland) to $96.0 \%$ (Puducherry) at the state level. ${ }^{2}$ Similarly, the coverage of full vaccination, namely, receiving BCG vaccine, three doses of DTP and oral polio vaccine (OPV3) and measles vaccine, was $62.0 \%$ at the national level, with variation from $35.4 \%$ (Nagaland) to $91.2 \%$ (Puducherry) at the state level in 2015-2016. Among all states in India, Nagaland has had the lowest or the second lowest coverage for full vaccination among children aged 12-23 months since early 1990s according to the decennial NFHS. Specifically, full vaccination coverage increased from $35.4 \%$ to $62.0 \%$ nationwide from 1992 to 1993 (NFHS-1) to 2015-2016 (NFHS-4); whereas in Nagaland, from $3.8 \%$ to $35.4 \%$ over the same period, which lags the national average around two decades. Despite the historically low childhood 
vaccination coverage in Nagaland, few studies have been

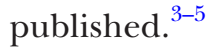

In Nagaland, routine vaccination is free of charge under Universal Immunisation Programme. ${ }^{6}$ Apart from parents or families bringing their children to health centres for vaccination, the Village Health and Nutrition Day (VHND) is an important platform for vaccination in Nagaland especially due to hilly geography and poor transportation and road infrastructure. VHND is a main outreach initiative under the National Rural Health Mission, through which health workers from health centres visit villages every month to provide free primary health services including vaccination.

Moving towards full vaccination of all children requires coordination among diverse groups especially from demand and supply sides and local health governance. Literature review by Tauil et al for nine developing countries in sub-Saharan Africa, Asia, and Latin America and four developed countries showed that local contexts mattered, but overall, parental socioeconomic status and mothers' access to healthcare services appeared to be associated with incomplete or delayed childhood vaccination. ${ }^{8}$ Arsenault $e t$ al showed in their meta-analyses across 45 developing countries in sub-Saharan Africa, Asia and Latin America that various factors on the demand side were associated with inequality of childhood vaccination, for example, maternal education and household economic status. ${ }^{9}$ Studies with focus on India showed similar results. Banerjee et al showed that incentivising people on the demand side by offering non-financial goods was a cost-effective approach in resource poor areas to improve childhood vaccination coverage..$^{10}$ Bhargava et al, Choudhary et al and others suggested that parents' education and awareness of benefits and schedules of vaccination and household wealth were associated with childhood vaccination. ${ }^{11-13}$ Francis et al showed that antenatal care was strongly linked to childhood vaccination coverage in India. ${ }^{14} 15$

With respect to the supply side, studies for Nigeria showed that vaccine stockouts and absence of vaccinators in health facility were barriers against childhood vaccination. ${ }^{16}{ }^{17} \mathrm{~A}$ study for Uganda showed that poor roads led to delayed delivery of vaccines and refrigerator gas, thereby deteriorating the effectiveness of outreach vaccination interventions. ${ }^{18}$ A study for Lao PDR showed that low vaccination coverage was associated with a lack of vaccine supply and competent health workers and difficulty in maintaining the cold chain. ${ }^{19}$ Similarly, Prinja $e t$ $a l$ showed that staff shortage and vaccine stockout were the main reasons for delayed vaccination in rural India. ${ }^{20}$ Ghosh and Laxminarayan showed that children living in a district with a higher number of healthcare subcentres were more likely to receive DTP vaccination in rural India. $^{21}$

Governance in the health sector is crucial to facilitate both demand and supply sides to function properly. India has a decentralised healthcare system. In Nagaland, village health committees are entitled to manage primary healthcare delivery and mobilise local resources at the village level under the Communitisation of Public Institutions and Services Act. ${ }^{22}{ }^{23}$ For managing health centres, health committees are constituted with representation from village health committees or village councils in their board and entitled to provide annual budget, review expenditure, and monitor and evaluate operation of health centres. Health centres consist of three tiers: subcentre and primary health centre at the primary level and community health centre at the secondary level. ${ }^{24}$ Village health committees and health centre committees collaborate to promote primary healthcare utilisation. VHND is a main activity that is organised under their cooperation. In practice, however, variations in accountability and effectiveness of local health committees have been observed. ${ }^{25}$ For instance, a process evaluation of a communitisation programme in Nagaland showed that insufficient or the lack of annual budget imposed major constraints in supplying drugs and equipping health centres with medical infrastructure, leading to poor healthcare service delivery. ${ }^{26}$ Another process evaluation of a community-support intervention in Nagaland showed that some members of village health committee were unaware of their responsibilities, and also many female co-chairs of the committees were nominal without actual participation. ${ }^{27}$

The nationwide surveys and the literature review have posed a question on why childhood vaccination coverage has been quite low in Nagaland given the findings of previous studies for India and other developing countries. To answer the question, this study analysed dataset from a survey conducted in 2015 from the perspective of demand, supply and local health governance.

\section{METHODS}

\section{Data source}

This study used dataset from a survey conducted from April to June 2015 by the Directorate of Health and Family of the state of Nagaland, with World Bank, to assess the demand and supply of primary health services. A three-stage cluster sampling method was used. First, non-functional health centres which did not meet following criteria for functionality were excluded: (1) having doctors, (2) undertaking childbirth, (3) having integrated counselling and testing centres, and (4) having more than 50 inpatient wards for community health centres and primary health centres; and (1) having doctors or auxiliary nurses/midwives and (2) undertaking childbirth for subcentres. After exclusion, a total of 101 health centres remained: all 21 community health centres in Nagaland, 55 primary health centres (44\% out of total 124 ) and 25 subcentres $(6 \%$ out of total 397). The subcentres were selected randomly among initially chosen 99 functional ones (25\% out of total) due to budget constraints. Second, one village was randomly chosen from the official list of villages in the catchment area of each of 96 health centres. For the remaining five 


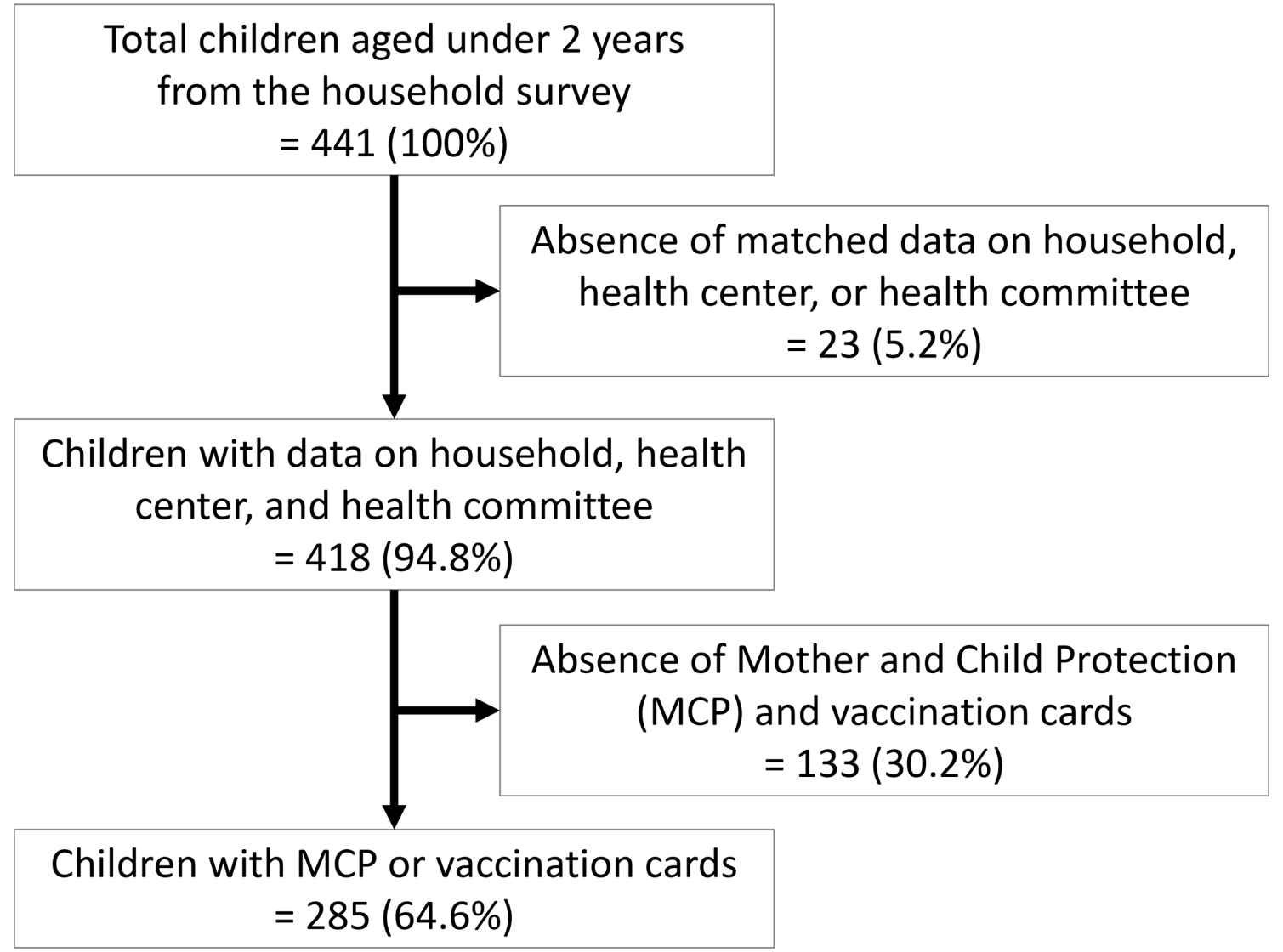

Figure 1 Sample selection process.

health centres (two community health centres and three subcentres), 14 villages had been already selected for a pilot study. A health centre at a higher level is supposed to cover wider areas; however, in practice, the lists of villages in the catchment areas did not overlap mainly because of hilly geography and poor transportation system. In total, 110 villages were selected. Lastly, at least 15 households from each village were randomly selected using a random walk approach. Surveys were conducted for households, health centres and local health committees in the selected villages.

\section{Study sample}

Among children aged under 2 years from the survey, children without data on households, health centres and local health committees were excluded. We then excluded children who did not have Mother and Child Protection (MCP) and vaccination cards because of inaccurate or missing records on vaccinations (figure 1 ). For the analysis of vaccination by antigen, we used the national vaccination schedule to determine the minimum age of corresponding samples: 0 week for bacilluscalmette-guérin (BCG), 14 weeks for DTP3 and OPV3, and 9 months for measles vaccination. ${ }^{28}$

\section{Patient and public involvement}

This study was done without involvement of patients or members of the public in the design, conduct, reporting and dissemination plans of the research.

\section{Statistical analysis}

Outcome variable

The outcome variables were binary, indicating whether a child received vaccination for BCG, DTP3, OPV3, measles and all.

\section{Independent variables}

Indicators of the demand side at the individual level were maternal and paternal education, antenatal care, childbirth in health centre and household wealth (table 1). Antenatal care was defined as binary with a threshold of three times, namely, 0 if less than three times and 1 if three times or more. The threshold was chosen based on the current statistics of antenatal care utilisation and a target set by the state government in a recent statewide health project. Specifically, the NFHS-4 (2015/2016) survey showed that the utilisation of antenatal care in Nagaland lagged far the national average. Particularly, the survey reported the lowest share of pregnant women who had at least one antenatal care visit among all states at $46 \%$, which is slightly higher than a half of the national average of $83 \% .{ }^{29}$ Considering the current low utilisation of antenatal care, the state government set a target for increasing the share of pregnant women who use antenatal care at least three times from $40 \%$ to $60 \%$ over the period 2018-2023 in the ongoing Nagaland Health Project, supported by World Bank. ${ }^{25}$ A household wealth index was constructed by combining data on house 
Table 1 List of indicators for demand and supply side and local health governance

\begin{tabular}{|c|c|c|}
\hline Indicator & Description & Values \\
\hline \multicolumn{3}{|l|}{ A. Demand (individual level) } \\
\hline Mother's education & $\begin{array}{l}\text { Mother's highest completed level of } \\
\text { education }\end{array}$ & $\begin{array}{l}0: \text { none; } \\
\text { 1: primary; }\end{array}$ \\
\hline Father's education & $\begin{array}{l}\text { Father's highest completed level of } \\
\text { education }\end{array}$ & $\begin{array}{l}\text { 2: secondary; } \\
\text { 3: tertiary and above }\end{array}$ \\
\hline Mother's antenatal care & Antenatal checkups at least three times & $0: 1-2$ times; $1: 3$ times or more \\
\hline Mother's institutional delivery & Childbirth in health centre & $0:$ no; $1:$ yes \\
\hline Household wealth & Tertiles of the wealth index & $\begin{array}{l}\text { 1: first tertile (poor); } \\
\text { 2: second tertile (medium); } \\
\text { 3: third tertile (rich) }\end{array}$ \\
\hline \multicolumn{3}{|l|}{ B. Supply (village level) } \\
\hline Type of health centre & Three levels of health centres & $\begin{array}{l}\text { 1: subcentre; } \\
\text { 2: primary health centre; } \\
\text { 3: community health centre }\end{array}$ \\
\hline Bus & Whether there is a bus to health centre & $0:$ no; 1 : yes \\
\hline Presence of medical staff in health centre & $\begin{array}{l}\text { Presence of doctors or nurses at the time } \\
\text { of survey visit }\end{array}$ & $\begin{array}{l}0: \text { no medical staff; } \\
\text { 1: at least one medical staff }\end{array}$ \\
\hline Stockout of vaccines & $\begin{array}{l}\text { Stockout of any vaccines among BCG, } \\
\text { DTP, OPV and measles vaccines in the } \\
\text { last } 6 \text { months based on vaccine registers }\end{array}$ & $\begin{array}{l}0: \text { no stockout; } \\
\text { 1: stockout }\end{array}$ \\
\hline \multicolumn{3}{|c|}{ C. Local health governance (village level) } \\
\hline Village Health and Nutrition Day (VHND) & $\begin{array}{l}\text { Village health committee's organisation of } \\
\text { VHND in the last month }\end{array}$ & $\begin{array}{l}0: \text { no; } \\
1: \text { yes }\end{array}$ \\
\hline $\begin{array}{l}\text { Budget allocation and expenditure review } \\
\text { for health centre }\end{array}$ & $\begin{array}{l}\text { Whether a health committee provided } \\
\text { annual budget to a health centre and } \\
\text { reviewed expenditure at least once a year }\end{array}$ & $\begin{array}{l}\text { 0: no budget provided; } \\
\text { 1: annual budget provided; } \\
\text { 2: expenditure reviewed }\end{array}$ \\
\hline
\end{tabular}

BCG, bacillus calmette-guérin; DTP, diphtheria-tetanus-pertussis; OPV, oral polio vaccine.

material, electronic assets, vehicle and livestock using the principal component analysis (online supplemental annex 1).

Indicators of the supply side and local health governance were at the village level (table 1 ). The supply side included the type of health centres, whether there was a bus to health centres, the presence of doctors or nurses in health centres during the survey visit, and vaccine stockout based on vaccine registers. Indicators for local health governance were (1) whether village health committees held the VHND, (2) whether health committees provided annual budget to health centres under their management and (3) whether health committees reviewed expenditure of health centres at least once a year after providing annual budget.

\section{Multilevel analysis}

Multilevel analysis was conducted to examine significant factors associated with vaccination coverage in three steps. First, we decided how many levels to include. According to the sampling design, there are two clusters, namely, children belonged to villages and then the catchment areas of health centres. However, considering a single village was selected from each catchment area for the majority of health centres, we compared two alternative null models with only village random effects and with both village and health centre random effects using log-likelihood ratio tests (LRTs). Second, we assessed one-on-one relationship between childhood vaccination and each indicator using bivariable multilevel logistic regressions. Lastly, we ran multivariable multilevel logistic regressions in which all significant indicators from the bivariable regressions were included as explanatory variables. The level of $5 \%$ and $10 \%$ was applied for being significant and slightly significant, respectively. In the last step, four consecutive models were built: model 0 with only an intercept, model 1 with individual-level variables, model 2 with village-level variables and model 3 with individual-level and village-level variables. Considering they were nested, log-likelihood was compared across the models. We used the command meqrlogit in Stata (V.15.0)..$^{30}$

\section{RESULTS}

\section{Study sample}

Among the 441 children aged under 2 years from the survey, $285(65 \%)$ children were chosen after excluding children without matched data on households, health 
Table 2 Average vaccination coverage for antigen-specific and full vaccinations

\begin{tabular}{lllll}
\hline Type of vaccination & Average & SD & Sample size & Age range of samples \\
\hline BCG & $81.40 \%$ & $38.98 \%$ & 285 & $0-23$ months \\
DTP, 3 doses & $70.80 \%$ & $45.57 \%$ & 226 & 14 weeks to 23 months \\
OPV, 3 doses & $66.37 \%$ & $47.35 \%$ & 226 & 14 weeks to 23 months \\
Measles & $66.67 \%$ & $47.29 \%$ & 156 & 9 months to 23 months \\
All (full vaccination) & $56.41 \%$ & $49.75 \%$ & 156 & 9 months to 23 months \\
\hline
\end{tabular}

BCG, bacillus calmette-guérin; DTP, diphtheria-tetanus-pertussis; OPV, oral polio vaccine.

centres and health committees and without MCP and vaccination cards (figure 1 ).

\section{Descriptive statistics}

Vaccination coverage for BCG, DTP3, OPV3, measles and all of them (full vaccination) are shown in table 2 . The average was $81 \%$ for BCG, between $66 \%$ and $71 \%$ for DTP3, OPV3 and measles, and 56\% for full vaccination. The summary of the indicators of demand, supply and local health governance is shown in table 3 .

\section{Multilevel analysis}

Levels

We included only village random effects based on the LRT for the alternative null models-one with only village random effects and another with random effects for both village and health centre. The LRT showed that there was no significant improvement by adding random effects for health centre (table 4). It is because village clusters are almost the same as health centre clusters in the collected data, because a single village was selected within each catchment area for almost all health centres.

\section{Bivariable logistic regressions}

Bivariable logistic regressions showed that significant variables at least for one dependent variable were mother's education, father's education, antenatal care checkups, childbirth in health centre, the wealth index, the availability of bus to health centre and health committee's budget provision and expenditure review for health centres (table 5). These variables were used as explanatory variables for multivariable models.

\section{Multivariable logistic regressions}

For all the five outcomes, model 3 with individual-level and village-level variables was chosen as the final model based on the highest log-likelihood, as shown in table 6 . Model 0 shows that between-village variance was significant, accounting for $20 \%-32 \%$ of total variance across all the outcomes. After controlling for the individual-level and village-level variables in model 3 , between-village variance became insignificant at the significance level of $5 \%$.

Full vaccination was significantly associated with mother's primary education with the adjusted OR (AOR) of 4.5 (95\% CI 1.3 to 15.0), antenatal care with the AOR of 3.3 (1.1 to 9.9), and health committee's annual budget provision and expenditure review for health centre with the respective AORs of 15.9 (1.2 to 214.7) and 5.2 (1.4 to 19.4) (table 7 ). The wide $95 \%$ CI for the budget provision was driven by a small number of unvaccinated children living in the catchment areas of health centres that received annual budget. The final model explained $28.5 \%$ of village-level variance (proportional change in variance $(\mathrm{PCV}))$, thereby reducing the intraclass correlation (ICC), that is, the share of between-village variance in total variance, from $32.4 \%$ in the null model to $25.5 \%$.

For BCG vaccination, antenatal care was significantly associated with the AOR of 2.7 (1.3 to 5.8). The availability of bus to health centres was slightly significant with the AOR of 2.0 (0.9 to 4.5). All children living in the catchment areas of health centres that received annual budget were vaccinated. The final model explained $48.4 \%$ of village-level variance $(\mathrm{PCV})$, leading to a decrease in the share of between-village variance in total variance (ICC) from $19.5 \%$ in the null model to $11.1 \%$.

For DTP3 vaccination, the significant variables were antenatal care and the medium wealth index as compared with the poor with the respective AORs of 2.4 (1.1 to 5.1) and 2.6 (1.1 to 6.0$)$. All children living in the catchment areas of health centres that received annual budget were vaccinated. The final model explained $31.9 \%$ of villagelevel variance (PCV), leading to a decline in the share of between-village variance in total variance from $23.0 \%$ in the null model to $16.9 \%$ (ICC).

OPV3 vaccination was significantly associated with antenatal care and the medium wealth index with reference to the poor with the AORs of 2.6 (1.2 to 5.5) and 3.3 (1.5 to 7.6), respectively. The availability of bus to health centres was slightly significant with the AOR of 2.1 (0.9 to 4.8). Health committee's provision of annual budget to health centre was significant with the AOR of 15.7 (1.0 to 234.1), the wide $95 \%$ CI of which was driven by a small number of unvaccinated children living in the catchment areas of health centres that received annual budget. The final model explained $38.0 \%$ of village-level variance (PCV), and the share of between-village variance in total variance decreased from $25.2 \%$ in the null model to $17.3 \%$ (ICC).

Lastly, measles vaccination was significantly related to mother's primary education and health committee's review of expenditure of health centre with the AORs of 2.8 (1.0 to 8.1) and 4.0 (1.4 to 11.4), respectively. The final model explained $63.3 \%$ of village-level variance (PCV), 
Table 3 Summary of indicators of demand and supply side and local health governance

\section{Total number of \\ children under 2 years \\ old}

285

Number

Per cent

\section{A. Demand}

Mother's highest level of education completed

$\begin{array}{lrc}\text { (1) None } & 71 & 24.91 \\ \text { (2) Primary } & 140 & 49.12 \\ \text { (3) Secondary } & 62 & 21.75 \\ \text { (4) Tertiary and above } & 12 & 4.21 \\ \text { (5) Missing } & 0 & 0\end{array}$

Father's highest level of education completed

$\begin{array}{lrc}\text { (1) None } & 71 & 24.91 \\ \text { (2) Primary } & 119 & 41.75 \\ \text { (3) Secondary } & 64 & 22.46 \\ \text { (4) Tertiary and above } & 31 & 10.88 \\ \text { (5) Missing } & 0 & 0\end{array}$

Antenatal care

$\begin{array}{lrc}\text { (1) } 1-2 \text { times } & 153 & 53.68 \\ \text { (2) } 3 \text { times or more } & 132 & 46.32 \\ \text { (3) Missing } & 0 & 0 \\ \text { Institutional delivery } & & \\ \text { (1) No } & 148 & 51.93 \\ \text { (2) Yes } & 137 & 48.07 \\ \text { (3) Missing } & 0 & 0 \\ \text { Wealth index } & & \\ \text { (1) Poor (first tertile) } & 107 & 37.54 \\ \text { (2) Middle (second } & 105 & 36.84 \\ \text { tertile) } & & \\ \text { (3) Rich (third tertile) } & 73 & 25.61 \\ \text { (4) Missing } & 0 & 0\end{array}$

\section{B. Supply}

Type of health centre

$\begin{array}{lrr}\text { (1) Subcentre } & 55 & 19.30 \\ \begin{array}{l}\text { (2) Primary health } \\ \text { centre }\end{array} & 170 & 59.65 \\ \begin{array}{l}\text { (3) Community health } \\ \text { centre }\end{array} & 60 & 21.05\end{array}$

Availability of bus to health centre

$\begin{array}{lrc}\text { (1) No } & 167 & 58.60 \\ \text { (2) Yes } & 118 & 41.40 \\ \text { (3) Missing } & 0 & 0\end{array}$

Presence of doctors or nurses at the time of survey

$\begin{array}{lrc}\text { (1) No } & 68 & 23.86 \\ \text { (2) Yes } & 217 & 76.14 \\ \text { (3) Missing } & 0 & 0\end{array}$

Stockout of vaccines in the last 6 months

Continued

\begin{tabular}{|c|c|c|}
\hline \multirow{2}{*}{$\begin{array}{l}\text { Total number of } \\
\text { children under } 2 \text { years } \\
\text { old }\end{array}$} & \multirow{2}{*}{$\begin{array}{l}285 \\
\text { Number }\end{array}$} & \multirow[b]{2}{*}{ Per cent } \\
\hline & & \\
\hline (1) No & 219 & 76.84 \\
\hline (2) Yes & 66 & 23.16 \\
\hline (3) Missing & 0 & 0 \\
\hline
\end{tabular}

C. Local health governance

Village Health and

Nutrition Day

$\begin{array}{lrr}\text { (1) Not organised } & 33 & 11.58 \\ \begin{array}{l}\text { (2) Organised in the } \\ \text { last month }\end{array} & 234 & 82.11 \\ \text { (3) Missing } & 18 & 6.32\end{array}$

Budget allocation and expenditure review for health centre

$\begin{array}{lll}\text { (1) No budget } & 73 & 25.61\end{array}$ provided

(2) Annual budget $\quad 12$
provided

(3) Expenditure $\quad 200 \quad 70.18$ reviewed at least once a year
(4) Missing
0
0

*Number (\%) of children who belong to the catchment areas of health centres or live in villages with specified characteristics.

and the share of between-village variance in total variance decreased from $25.8 \%$ in the null model to $11.3 \%$.

The model building process from model 0 to model 3 is reported in detail in the online supplemental annex 2.

\section{DISCUSSION}

This study examined drivers and barriers in enhancing childhood vaccination coverage in Nagaland from the aspects of demand, supply and local health governance. Significantly associated variables were different across antigen-specific and full vaccinations. However, most outcomes were significantly related to antenatal care at least three times, followed by local health committees' budget provision and expenditure review for health centres. The availability of bus to health centres was slightly significant.

The findings suggest potential determinants of childhood vaccination and present policy implications. On the demand side, the most often associated factor was antenatal care. This finding is consistent with previous studies. Herliana and Douiri showed in their cross-sectional study for Indonesia that receiving no antenatal care was significantly associated with non-vaccination of children. ${ }^{31}$ Boulton et al showed in a cross-sectional study for Bangladesh that children of mothers who did not receive antenatal care were less likely to be fully vaccinated. ${ }^{32}$ Similarly, a study using the District Level Household and Facility 
Table 4 Log-likelihood ratio tests for alternative null models with only village random effects and both village and health centre random effects

\begin{tabular}{llllll}
\hline & Full & BCG & DTP3 & OPV3 & Measles \\
\hline $\mathrm{N}$ & 156 & 285 & 226 & 226 & 156 \\
\end{tabular}

Log-likelihood ratio test comparing two null models with village RE only and village and health centre RE

\begin{tabular}{lrrrrr} 
Chi-squared statistics, $\chi^{2}(1)$ & 1.46 & -0.00 & 0.39 & 1.33 & -0.00 \\
Log-likelihood ratio test, $p$ value & 0.23 & 1.00 & 0.53 & 0.25 & 1.00 \\
\hline
\end{tabular}

BCG, bacillus calmette-guérin; DTP3, diphtheria-tetanus-pertussis (three doses); OPV3, oral polio vaccine (three doses); RE, random effects.

Survey 2008 (DLHS 3) by Shrivastwa et al and another study using the consecutive DLHS data over 1998-2008 (DLHS 1-3) by Francis et al showed that antenatal care was significantly linked to childhood vaccination in India. ${ }^{1433}$ A causal link from antenatal care to childhood vaccination was not clearly proved in the previous studies. However, the significant association suggests that mothers who received antenatal care more frequently tend to be more motivated to vaccinate their children. This, in turn, suggests that not only organising health education campaigns and village outreach programmes but also encouraging and supporting community health workers to identify pregnant women and follow them up with timely notifications on antenatal check-ups are important in enhancing childhood vaccination coverage.

In this study, parents' socioeconomic status was not always associated with vaccination coverage. Mother's primary education was significantly correlated with full and measles vaccinations. However, for BCG, DTP3 and OPV3 vaccinations, maternal education was not significant. Paternal education was not associated with all vaccinations. The medium wealth index was significantly associated with DTP3 and OPV3 as compared with the poor. However, for BCG, measles and full vaccinations, the wealth index was not significant. These results may be because what matters the most was mother's awareness of and motivation for childhood vaccination than parents' education and household wealth. This is implied by the significance of antenatal care visits because frequent antenatal check-ups usually lead to repeated face-toface communications with health providers. Francis et al showed similar results in a cross-sectional study for rural areas in southern India that giving the information on vaccination to mothers during their antenatal check-ups had a significant association with childhood full vaccination, while sociodemographic variables such as parents' education and occupation and the type of dwellings as a proxy for household wealth were not associated. ${ }^{15}$

The results showed all supply-side indicators except for the availability of bus to health centres, namely, the type of health centre, the presence of medical staff and vaccine stockout, were not significantly associated. These findings are in line with other studies. Tauil et al showed in their literature review on DTP3, OPV3 and measles vaccinations among children aged under 2 years across developed and developing countries that most relevant factors to childhood vaccination belong to parents' and household characteristics rather than supply-side factors. ${ }^{8}$ Francis $e t$ $a l$ showed that, for the period 1998-2008 in India, the most prevalent reasons for non-vaccination among children aged 12-23 months were not related to the supply side, but to demand-side characteristics such as parents' awareness of and financial and non-financial affordability of vaccination. ${ }^{14}$ Ghosh and Laxminarayan showed that the availability of health facilities and vaccination-related health workers were not associated with completion of DTP3 in rural areas of India; instead, maternal and household characteristics were significantly associated. ${ }^{21}$ The quality of health centres in terms of medical staff, medical supplies and infrastructure is crucial for providing vaccinations; however, this and previous studies suggest that without a demand or effective local health governance, the supply side alone is less likely to improve childhood vaccination.

Local health governance at the community level was significantly associated with childhood vaccination. All children who received BCG and DTP3 lived in the catchment areas of health centres with annual budget. For OPV3 and full vaccination, health committee's annual budget provision for health centre was significantly associated. Also, living in the catchment areas of health centres of which expenditure was reviewed by health committees at least once a year was significantly related to receiving measles and full vaccination. These results are consistent with the findings of previous literature that the budgetary and financial administration of local health governments is important in enhancing primary health service utilisation. Tushi and Kaur showed in a process evaluation of Health Centre Managing Committees in Nagaland that an inadequate or delayed budget from the state government was a major barrier in budget administration, which caused a delay in salary payment to health facility staff and a difficulty in mobilising local resources to provide health services. ${ }^{26}$ Seshadri et al showed in a case study of the state of Karnataka, India, that a greater perception of autonomy in budgeting and financing among Health Department officials and local health governments at the district level and below was significantly associated with health service utilisation including childhood vaccination. ${ }^{34}$ They also found that a perception of empowerment in conducting official functions including budget administration and monitoring 


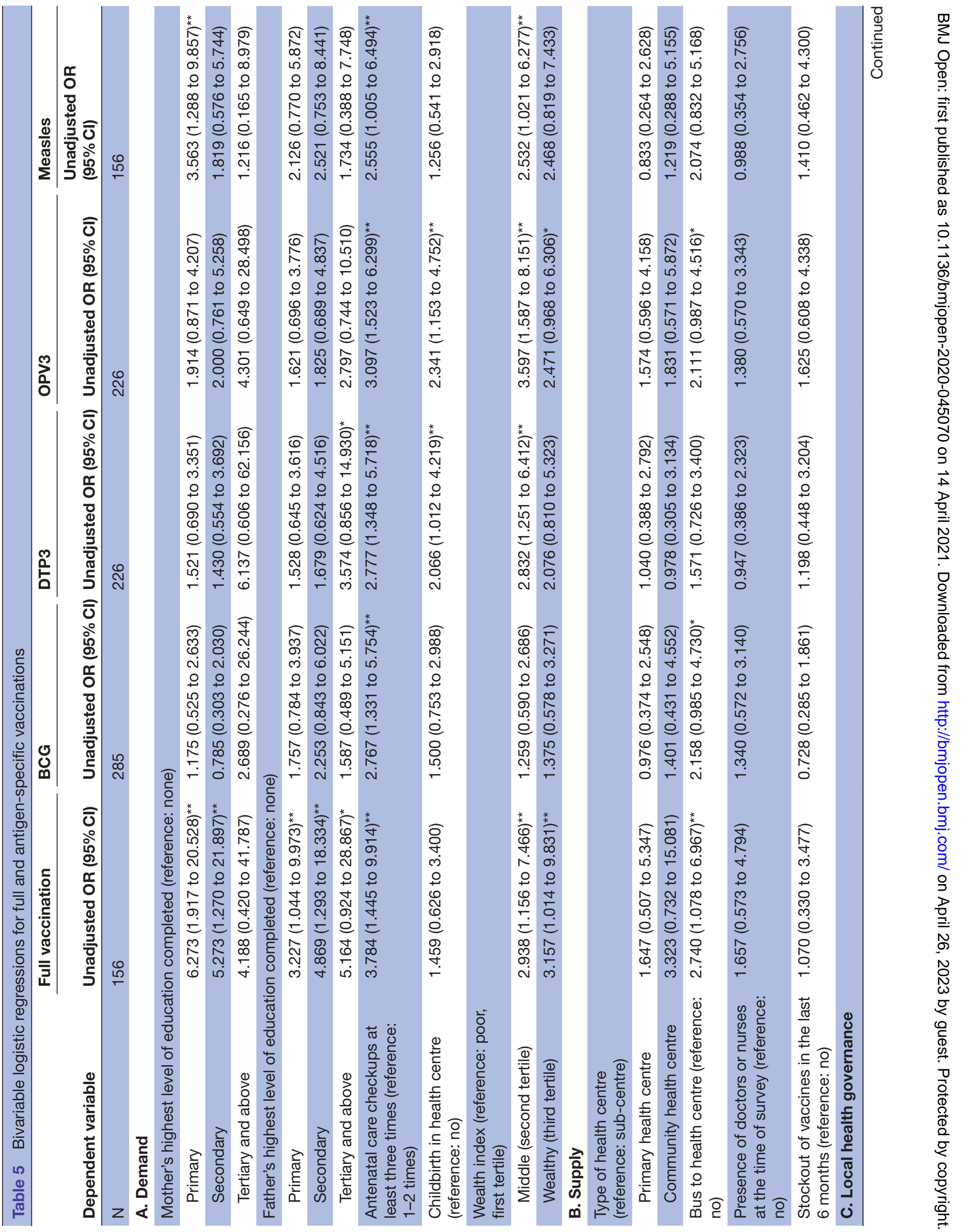


among health officials and local health governments was significantly lower in districts with a lower level of health and education. These findings suggest that it is important for policy makers to allocate sufficient budget for local health governance, simplify administrative procedures for budgeting for health centres, make a clear guideline for health committees to review and monitor expenditure of health centres, and capacitate health committee members through regular training on their roles and responsibilities.

Organising VHND, another indicator of local health governance, was not significant. Previous studies showed that the effectiveness of VHND differed across local settings. Johri et al showed in their process evaluation of VHND in rural areas in Uttar Pradesh that while key services including antenatal care and vaccination were provided during VHND, other basic services such as health education and promotion and the identification and tracking of beneficiaries were weak. ${ }^{35}$ Newton-Lewis et alshowed in their qualitative study on community-based health committees in Nagaland that local health committees were supposed to coordinate with community health workers in organising VHND; however, only some of them did. ${ }^{36}$ Panigrahi $e t$ al suggested in their study for the state of Odisha that there was a lack of community health workers' awareness of their responsibilities in organising VHND and also a lack of awareness among beneficiaries on the schedule and purpose of VHND. ${ }^{37}$ As these studies suggest, there could be several reasons for the nonsignificant result for VHND, for instance, the absence of effective coordination among health committees and health providers and the lack of beneficiaries' awareness of VHND. This insignificant association between VHND and childhood vaccination needs more research to identify barriers, for example, through a process evaluation of VHND with structural interviews of health committee members, community health workers and beneficiaries.

This study has limitations. First, the dataset was not representative of the entire households, health centres and health committees in Nagaland. Specifically, people living in the catchment areas of non-functional health centres were excluded in the sampling. Although the results suggest that almost all indicators of the supply side were not significantly associated with childhood vaccination, the results might have been different if non-functional health centres and households in their catchment areas had been included. Second, children without vaccination cards were excluded. It may result in selection bias. The results might have been different if they had been included. Third, there could be other representative indicators for demand, supply and local health governance. However, the selection of indicators was restricted to available dataset from the survey. Lastly, the indicators do not measure qualitative aspects. For example, the quality of antenatal care and medical staff and the managerial capacity of local health committees are important but could not be incorporated due to the absence of data. 
Table 6 Multilevel analysis: random effects estimates and the goodness of fit

\section{Model $0 \quad$ Model 1}

Model 2

Model 3

\section{Full vaccination}

\section{Random effects}

Village-level variance (SE)

$1.578(1.113)^{\star *}$

$2.732(2.123)^{\star *}$

$0.586(0.740)$

$1.129(1.319)$

Intraclass correlation (ICC)

$32.4 \%$

$45.4 \%$

$15.1 \%$

$25.5 \%$

Proportional change in variance (PCV)

Reference

$-73.1 \%$

$62.9 \%$

$28.5 \%$

\section{Goodness of fit}

$\begin{array}{lllll}\text { Akaike information criterion (AIC) } & 211.957 & 206.257 & 205.560 & 198.686 \\ \text { Log-likelihood } & -103.978 & -91.128 & -97.780 & -84.343\end{array}$

II. BCG

Random effects

\begin{tabular}{|c|c|c|c|c|}
\hline Village-level variance (SE) & $0.796(0.565)^{\star *}$ & $0.792(0.606)^{\star *}$ & $0.400(0.443)$ & $0.411(0.480)$ \\
\hline ICC & $19.5 \%$ & $19.4 \%$ & $10.8 \%$ & $11.1 \%$ \\
\hline PCV & Reference & $0.5 \%$ & $49.7 \%$ & $48.4 \%$ \\
\hline \multicolumn{5}{|l|}{ Goodness of fit } \\
\hline AIC & 273.810 & 280.594 & 268.721 & 275.433 \\
\hline Log-likelihood & -134.905 & -128.297 & -129.360 & -122.716 \\
\hline \multicolumn{5}{|l|}{ III. DTP3 } \\
\hline \multicolumn{5}{|l|}{ Random effects } \\
\hline Village-level variance (SE) & $0.981(0.675)^{\star \star}$ & $1.192(0.844)^{\star \star}$ & $0.507(0.531)$ & $0.668(0.666)$ \\
\hline ICC & $23.0 \%$ & $26.6 \%$ & $13.3 \%$ & $16.9 \%$ \\
\hline PCV & Reference & $-21.5 \%$ & $48.3 \%$ & $31.9 \%$ \\
\hline \multicolumn{5}{|l|}{ Goodness of fit } \\
\hline AIC & 272.229 & 274.312 & 266.218 & 268.935 \\
\hline Log-likelihood & -134.115 & -125.156 & -128.109 & -119.468 \\
\hline \multicolumn{5}{|l|}{ IV. OPV3 } \\
\hline \multicolumn{5}{|l|}{ Random effects } \\
\hline Village-level variance (SE) & $1.111(0.697)^{\star *}$ & $1.237(0.831)^{\star \star}$ & $0.602(0.540)$ & $0.689(0.642)$ \\
\hline ICC & $25.2 \%$ & $27.3 \%$ & $15.5 \%$ & $17.3 \%$ \\
\hline PCV & Reference & $-11.3 \%$ & $45.8 \%$ & $38.0 \%$ \\
\hline \multicolumn{5}{|l|}{ Goodness of fit } \\
\hline AIC & 286.226 & 282.249 & 281.573 & 277.952 \\
\hline Log-likelihood & -141.113 & -129.125 & -135.787 & -123.976 \\
\hline \multicolumn{5}{|l|}{ V. Measles } \\
\hline \multicolumn{5}{|l|}{ Random effects } \\
\hline Village-level variance (SE) & $1.146(0.967)^{\star \star}$ & $1.352(1.231)^{\star \star}$ & $0.371(0.685)$ & $0.421(0.829)$ \\
\hline ICC & $25.8 \%$ & $29.1 \%$ & $10.1 \%$ & $11.3 \%$ \\
\hline PCV & Reference & $-18.0 \%$ & $67.6 \%$ & $63.3 \%$ \\
\hline \multicolumn{5}{|l|}{ Goodness of fit } \\
\hline AIC & 199.389 & 204.222 & 196.280 & 200.102 \\
\hline Log-likelihood & -97.695 & -90.111 & -93.140 & -85.051 \\
\hline
\end{tabular}

Model 0 includes only an intercept; model 1 includes only individual-level variables; model 2 includes only village-level variables; and model 3 includes individual-level and village-level variables. Significance at the level of $5 \%$ is marked with **.

BCG, bacillus calmette-guérin; DTP3, diphtheria-tetanus-pertussis (three doses); OPV3, oral polio vaccine (three doses). 


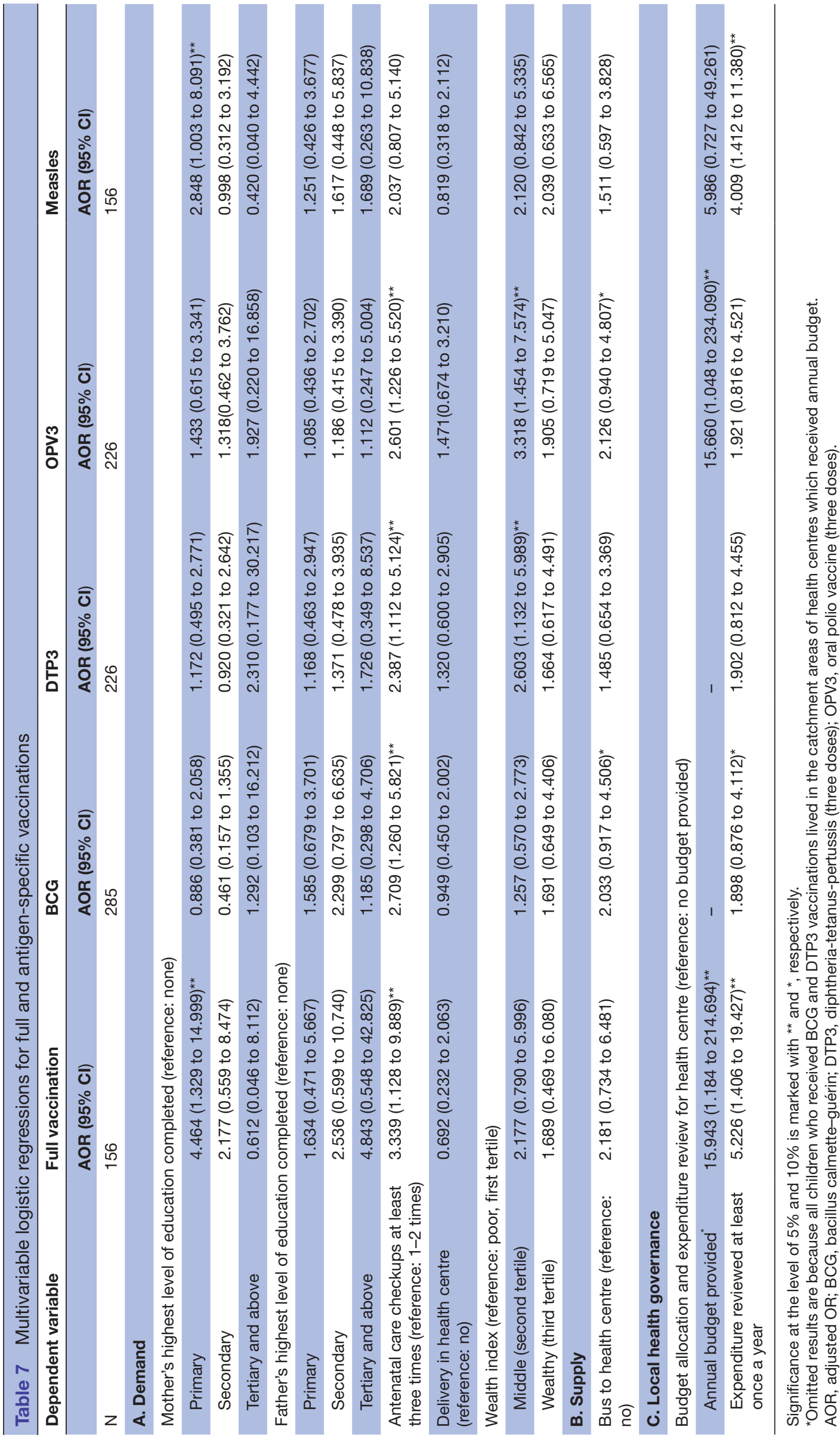

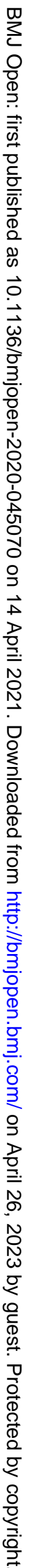




\section{CONCLUSION AND RECOMMENDATION}

At the individual level, antenatal care was the significantly associated factor with almost all outcomes. At the village level, the availability of bus to health centre was slightly significant; and health committee's budget provision and expenditure review for health centre were significant. The findings suggest that enhancing the utilisation of antenatal care and providing reliable transportation to health centre are needed. Also, supporting village-based health committees for effective financial management is important.

Acknowledgements Aarushi Bhatnagar (World Bank), Zeleke Mekonnen (University of Gondar College of Medicine and Health Sciences), Patrick Mullen (World Bank), Valerie Seror (INSERM), and the Project Management Unit, Nagaland Health Project, Government of Nagaland are greatly appreciated for reviewing the manuscript and giving valuable comments. Oxford Policy Management Ltd. collected data.

Contributors YEK: Study design, analysis, interpretation and preparation of the manuscript.

Funding The author has not declared a specific grant for this research from any funding agency in the public, commercial or not-for-profit sectors.

Competing interests None declared.

Patient consent for publication Not required.

Ethics approval Ethical approval for the survey was obtained from Institutional Ethics Committee, Public Health Foundation of India.

Provenance and peer review Not commissioned; externally peer reviewed. Data availability statement № data are available.

Supplemental material This content has been supplied by the author(s). It has not been vetted by BMJ Publishing Group Limited (BMJ) and may not have been peer-reviewed. Any opinions or recommendations discussed are solely those of the author(s) and are not endorsed by BMJ. BMJ disclaims all liability and responsibility arising from any reliance placed on the content. Where the content includes any translated material, BMJ does not warrant the accuracy and reliability of the translations (including but not limited to local regulations, clinical guidelines, terminology, drug names and drug dosages), and is not responsible for any error and/or omissions arising from translation and adaptation or otherwise.

Open access This is an open access article distributed in accordance with the Creative Commons Attribution Non Commercial (CC BY-NC 4.0) license, which permits others to distribute, remix, adapt, build upon this work non-commercially, and license their derivative works on different terms, provided the original work is properly cited, appropriate credit is given, any changes made indicated, and the use is non-commercial. See: http://creativecommons.org/licenses/by-nc/4.0/.

ORCID iD

Young Eun Kim http://orcid.org/0000-0002-6417-5956

\section{REFERENCES}

1 WHO. "Global and regional immunization profile,", 2019. Available: https://www.who.int/immunization/monitoring_surveillance/data/gs gloprofile.pdf?ua=1 [Accessed 3 Mar 2021].

2 International Institute for Population Sciences, "National Family Health Survey, India, 2020. Available: http://rchiips.org/nfhs/ [Accessed 3 Mar 2021].

3 Longvah Tet al. "Mother and child nutrition among the Chakhesang tribe in the state of Nagaland, North-East India,". Matern. Child Nutr 2017.

4 Rajbangshi P, Nambiar D, Choudhury N, et al. Rural recruitment and retention of health workers across cadres and types of contract in north-east India: a qualitative study. WHO South-East Asia J Public Health 2017;6:51-9.

5 Panda BK, Kumar G, Awasthi A. District level inequality in reproductive, maternal, neonatal and child health coverage in India. BMC Public Health 2020;20:58.
6 India Ministry of Health and Family Welfare, "National Health Mission: Immunization,", 2020. Available: https://nhm.gov.in/index1.php? lang=1\&level=2\&sublinkid=824\&lid=220 [Accessed 4 Sep 2020].

7 India Ministry of Health and Family Welfare, "National Health Mission: Village Health and Nutrition Day (VHND),", 2013. Available: http://164.100.154.238/communitisation/village-health-nutrition-day. html [Accessed 4 Sep 2020].

8 Tauil MdeC, Sato APS, Waldman EA. Factors associated with incomplete or delayed vaccination across countries: a systematic review. Vaccine 2016;34:2635-43.

9 Arsenault C, Harper S, Nandi A, et al. Monitoring equity in vaccination coverage: a systematic analysis of demographic and health surveys from 45 Gavi-supported countries. Vaccine 2017;35:951-9.

10 Banerjee AV, Duflo E, Glennerster R, et al. Improving immunisation coverage in rural India: clustered randomised controlled evaluation of immunisation campaigns with and without incentives. BMJ 2010;340:c2220.

11 Bhargava A, Guntupalli AM, Lokshin M, et al. Modeling the effects of immunizations timing on child health outcomes in India. Health Econ 2014;23:606-20.

12 Choudhary M, Solomon R, Awale J, et al. Demand-side determinants of timely vaccination of oral polio vaccine in social mobilization network areas of core group polio project in Uttar Pradesh, India. BMC Infect Dis 2018;18:222.

13 Choudhary TS, Reddy NS, Apte A, et al. Delayed vaccination and its predictors among children under 2 years in India: Insights from the national family health survey-4. Vaccine 2019;37:2331-9.

14 Francis MR, Nohynek $\mathrm{H}$, Larson $\mathrm{H}$, et al. Factors associated with routine childhood vaccine uptake and reasons for non-vaccination in India: 1998-2008. Vaccine 2018;36:6559-66.

15 Francis MR, Nuorti JP, Kompithra RZ, et al. Vaccination coverage and factors associated with routine childhood vaccination uptake in rural Vellore, southern India, 2017. Vaccine 2019;37:3078-87.

16 Gooding E, Spiliotopoulou E, Yadav P. Impact of vaccine stockouts on immunization coverage in Nigeria. Vaccine 2019;37:5104-10.

17 Sato R. Differential determinants and reasons for the non- and partial vaccination of children among Nigerian caregivers. Vaccine 2020;38:63-9.

18 Malande OO, Munube D, Afaayo RN, et al. Barriers to effective uptake and provision of immunization in a rural district in Uganda. PLoS One 2019;14:e0212270.

19 Phimmasane M, Douangmala S, Koffi P, et al. Factors affecting compliance with measles vaccination in Lao PDR. Vaccine 2010;28:6723-9.

20 Prinja S, Gupta M, Singh A, et al. Effectiveness of planning and management interventions for improving age-appropriate immunization in rural India. Bull World Health Organ 2010;88:97-103.

21 Ghosh A, Laxminarayan R. Demand- and Supply-side determinants of diphtheria-pertussis-tetanus nonvaccination and dropout in rural India. Vaccine 2017;35:1087-93.

22 Government of India, "The Nagaland Communitisation of Public Institutions and Services Act, 2002," 2002. Available: https:// www.nagaland.gov.in/Nagaland/UsefulLinks/The Nagaland Communitisation of Public Institutions and Services Act, 2002.pdf [Accessed 4 Sep 2020].

23 Government of India, "Village Health Sanitation \& Nutrition Committee,", 2021. Available: https://nhm.gov.in/index1.php?lang= 1\&level=1\&sublinkid=149\&lid=225 [Accessed 3 Mar 2021]

24 India Ministry of Health and Family Welfare, "Human Resources for Health," in High Level Expert Group Report on Universal Health Coverage for India 2011.

25 World Bank, "India - Nagaland Health Project,", 2016. Available: http://documents.worldbank.org/curated/en/719521482375675651/ India-Nagaland-Health-Project [Accessed 4 Sep 2020].

26 Tushi A, Kaur P. Process evaluation of Communitisation programme in public sector health facilities, Mokokchung district, Nagaland, 2015. Indian J Community Med 2017;42:81-7.

27 World Bank, "Process Evaluation of Community Result-Based Financing for Health and Nutrition in Nagaland, India: Lessons from Early Implementation,”, 2019. Available: http://documents. worldbank.org/curated/en/415381564517118342/ProcessEvaluation-of-Community-Result-Based-Financing-for-Health-andNutrition-in-Nagaland-India-Lessons-from-Early-Implementation [Accessed 03 Mar 2021].

28 India Ministry of Health and Family Welfare, "National Immunization Schedule,", 2018. Available: https://nhm.gov.in/New_Updates_2018/ NHM_Components/Immunization/report/National_Immunization_ Schedule.pdf [Accessed 4 Sep 2020].

29 Government of India, "National Family Health Survey (NFHS-4),", 2017 
30 StataCorp., "meqrlogit - Multilevel mixed-effects logistic regression (QR decomposition),", 2014. Available: https://www.stata.com/ manuals15/memeqrlogit.pdf [Accessed 23 Feb 2021].

31 Herliana P, Douiri A. Determinants of immunisation coverage of children aged 12-59 months in Indonesia: a cross-sectional study. BMJ Open 2017;7:e015790.

32 Boulton ML, Carlson BF, Power LE, et al. Socioeconomic factors associated with full childhood vaccination in Bangladesh, 2014. Int J Infect Dis 2018;69:35-40.

33 Shrivastwa N, Gillespie BW, Kolenic GE, et al. Predictors of vaccination in India for children aged 12-36 months. Am J Prev Med 2015;49:S435-44.
34 Seshadri SR, Parab S, Kotte S, et al. Decentralization and decision space in the health sector: a case study from Karnataka, India. Health Policy Plan 2016;31:171-81.

35 Johri M, Rodgers L, Chandra D, et al. Implementation fidelity of village health and nutrition days in Hardoi district, Uttar Pradesh, India: a cross-sectional survey. BMC Health Serv Res 2019;19:756.

36 Newton-Lewis T, Singh P, Saith R, et al. "Knowledge Brief: Community Action for Health and Nutrition in North East India," 2015.

37 Panigrahi S, Mohapatra B, Mishra K. Awareness, perception and practice of stakeholders in India regarding village health and nutrition day. J Family Med Prim Care 2015;4:244-50. 